\title{
LEGAL SKILLS TRAINING: SOME THOUGHTS ON TERMINOLOGY AND ONGOING CHALLENGES
}

\author{
JOHN H WADE*
}

\begin{abstract}
"Law schools are insufficiently theoretical; and insufficiently practical.” (Mudd)

"For what purposes should what be taught in what sequence to whom by whom using what methods in what milieux with what resources and with what feedback.” (Twining expanded)
\end{abstract}

\section{AIM}

This paper aims to set out briefly the grand goals of law school education; to struggle with the perhaps esoteric definitional problem of which goals might be labelled as "skills"; and to catalogue some of the hurdles/challenges to teaching and learning of skills at law schools.

\section{DEFINITION AND DESCRIPTION}

What is a "skill”? One definition is "Expertness, practised ability, facility in an action or in doing or to do something”. 1

Breaking down this particular definition of a skill suggests three elements of action, practice and a degree of competence. Thus learning a "skill” will usually involve doing, doing repetitively, and doing until a level of objective competence is achieved. The adjective "skilled” (skilled negotiator, skilled drafter) usually describes an action which has been practised to a high level of efficiency.

While wrestling with an appropriate description of a "skill”, Karl Mackie² commented:

"While no single definition of a skill has won universal acceptance amongst educational psychologists, one can list the main features which characterise 'skilled behaviour' as:

- goal-directed - behaviour which is directed towards achieving a desired result (rather than being a product of chance or accident);

- learnt — built up gradually by practice rather than being reflexive or instinctive;

- involves co-ordinated activity that is responsive to the environment using one's perceptions of a situation to make appropriate choices of behaviour necessary to achieve the desired purpose (eg whether to reflect feelings in a client interview; whether to use open or closed questions). A skill, therefore, involves a sequence of choices; actions and reactions;

- involves a repertoire of micro-skills - effective performance can generally be analysed into various elements or sub-routines (eg listening skills — showing attention and interest non-verbally, providing acknowledgments, restating client statements, reflecting feeling to demonstrate empathy);

- the transition from learning to accomplishment is generally accompanied by a shift to intuitive levels of response for micro-skill elements - learning a skill such as driving a car initially tends to render the separate elements of the activity mechanical or artificial. However, with practice, elements of the skill and co-ordination of those elements, tend to become almost 'automatic' and the 'player' can begin to concentrate on the more global activity (driving from here to there) or to single out other elements of a situation without disrupting performance (talking to other passengers). (This automaticity can later create difficulties if these actions need to change or have been learned in inappropriate ways - 'unlearning' habits accounts for many of the difficulties adults face in learning situations. They may for example have learned their listening skills in childhood in a manner that is inappropriate to a professional context, eg learned to interrupt others rather than to listen.)” 
What is obvious from dictionary and other definitions is that the concept of "skills" is flexible. It can be narrowed down; or broadened to catch virtually every kind of knowledge. The meaning of "skill” can also be varied based on an ascending level of competency from beginner to expert. Moreover the definition of "skills" can be manipulated for many purposes including:

- to defend against any pressure to change teaching/learning goals ("we have always been teaching skills");

- to apply for financial grants which promote "skills” learning;

- to attack a diet of memory and writing abilities as not being really skills "in the true sense";

- to defuse the current skills movement (in some law schools and elsewhere) as being "nothing new";

- to denigrate the desire to acquire skills as a lowly desire for technical or plumbing competence ${ }^{3}$ which competencies can be acquired readily and more appropriately at some other time in a short time.

In summary, the debates about the merits and demerits of "skills" training readily deteriorate when there is a failure to attempt to define terms. There is room for someone to develop a new vocabulary, conceptual framework and spectrum involving "skills”, “micro skills”, “sub-skills”, “techniques”, “tasks”, “transactions”, “intuition”, “art”, “science”, “competency”, “mastery”, and “style”.

\section{THE AWESOME GOALS OF LAW SCHOOLS}

Of the traditional or common goals of legal education, which might be classified as "skills", and which might be something else? One of the problems for law schools, professional legal trainers, law firms and for continuing legal educators, is that the goals of legal education are quite overwhelming. Tritely, it is suggested that lawyers, reclassified as modern-day problem analysts, need to know something about everything, and almost everything about something. That is, they need to have vast generalised knowledge, skills and attitudes, and a detailed specialist area of knowledge. Therefore, it is easy for anyone to assert that legal training should include Area X. Area X could cover anything from deep sea fishing industry to causes of depression. "Everything is useful" is the ubiquitous catchcry. Nevertheless, what follows is a more limited, but still breathtaking list of common goals of legal education (in random order): ${ }^{4}$

1 Learning and/or rote memorisation of certain rules and policies.

2 The ability to manipulate rules and policies orally and in writing.

3 The ability to systematise and criticise rules and policies basing the critique on logic, linguistics, various schools of philosophy, sociology, ethics and economics.

4 The development of broad abilities of research into legal materials; research into "other" materials; writing clearly; drafting precise documents; public speaking; advocacy; communication; interviewing and advice-giving ("counselling” in North America); ${ }^{5}$ organising allegations of facts and evidence of facts; negotiation; mediation; problem identification/problem solving; management of time, people, paper and resources; ways of knowing; self-reflection and evaluation.

$5 \quad$ Learning about and critiquing various philosophies of law.

6 The study of the sociology of law and lawyering.

7 The study of the psychology of lawyering and the psychology of conflict.

8 The study of various histories of law and legal systems.

9 The identification of certain ethical dilemmas and possible responses to these. ${ }^{6}$

10 The study of different cultural behavioural patterns - individual, corporate and legal.

11 Learning the theories and methods of managing and planning for social change (macro "problem solving”).

12 Learning to apply generic skills and knowledge to more particular transactions which are often peculiar to a traditional legal industry. These transactions include writing pleadings, writing letters of demand, drafting partnership deeds, buying and selling real estate or chattels, obtaining probate for a will, understanding what a balance sheet hides and discloses.

13 Stirring the emotions and providing an environment to inspire short or long term allegiance to a number of values and ideals - for example, due process; tenacity in the face of opposition, persistence and patience; compassion for the oppressed and dispossessed, (eg the poor, racially disadvantaged, children, women, ${ }^{7}$ mentally and physically handicapped, aged, the unborn, the 
uneducated, the violated), various versions of "justice"; care for the environment, service towards others, dedication to lifelong learning.

14 Developing character and habits (which may persist beyond ephemeral emotional attachment) towards commitment to certain values and principles - for example, those values set out in the previous paragraph.

It is fascinating to reflect on the pre-eminence given to character traits by practising lawyers. For example, Mudd and La Trielle surveyed all "active” practising lawyers in Montana by setting out 149 items of competency which fell into four general categories namely — knowledge of substantive and procedural law, technical skills and personal attributes. ${ }^{8}$ The respondents answered this question - "Based on your experience, what level of competence should a lawyer have in order to perform in a professionally competent manner?” by ranking the following competencies as most important. It is startling to see the majority of these top ranking competencies are character traits and commitments. ${ }^{9}$

(i) possesses the trait of honesty

(ii) possesses the trait of integrity

(iii) capacity to act ethically

(iv) possesses the trait of reliability

(v) possesses the trait of judgment

(vi) capacity to analyse

(vii) capacity to communicate effectively in writing

(viii) possesses the trait of maturity

(ix) capacity to approach tasks in a thorough fashion

(x) capacity to deal effectively with others

(xi) capacity to separate a multi-faceted legal problem into its legal parts

This brief list of fourteen goals of legal education can be expanded or systematised into taxonomies. ${ }^{10}$ There is an ongoing power struggle concerning which of these goals should attract resources, priority and compulsion.

\section{WHICH LAW SCHOOL GOALS ARE "SKILLS”?}

Which of this list of goals of legal education can be classified as a "skills"? In one sense, all of them. All involve action, practice and a measured degree of competence. Certainly at the most basic level of learning, memorisation of rules and policies involves the activity of training memory by strategies, pneumonics, behavioural modification (rewards with exercise, chocolate and television) and above all, repetition. The abilities to analyse, systematise and critique human behaviour and policies are also "doing" activities which can be learned by explanation, breaking into segments, modelling, repetitive practice and constructive feedback. ${ }^{11}$

If the acquisition of "knowledge" requires the exercise of a number of "skills", what about the acquisition of values? Is that a "skill"? This raises the tension between believing oneself into action, and acting oneself into believing. ${ }^{12}$ To some extent values held by inspiration, commitment or habit are often:

- made more reflexive and subconscious by repetitively practising responses to certain situations during role plays and simulations

- made more defensible by being systematised orally and in writing thereby finding organisational and historic roots Thus although the initial commitment to a value may often be a mystical and cosmic event, the development of commitment and that value seems to more readily fit within the broad description of a skill — repetitive practice towards a measurable standard.

If the above analysis is correct, every goal of legal education involves the teaching of skills. Skills are inescapable. They are inevitable. By acts of self and corporate delusion, a number of law school teachers sometimes convince themselves otherwise.

\section{NARROWING THE MEANING OF “SKILLS”?}

Anecdotally, the word "skills" appears to be used to describe a narrow range of educational goals - for example categories 4, 9 and 12. These goals include writing, interviewing, communication, advocacy, 
identifying ethical issues and more technical transaction skills.

Such "skills" categories supposedly involve a greater degree of physical activity both in the method of learning and the ultimate goal achieved. The goals excluded as "skills" supposedly involve a greater degree of reflection and "internal cognitive" activity. It is acknowledged that the conceptual distinction is fragile if not spurious as:

- thinking is an activity improved by consciously learned and repetitively drilled strategies;

- skills (eg drafting, interviewing, negotiation) are probably more effectively learned by developing a number of theories behind each skill which theories are then subject to a range of critiques.

It can of course, be argued that the word "skills" is unhelpful as it is too vague and overlaps so frequently with cognitive or intellectual or value goals. If that proposition is accepted, then university legal education over the last hundred years has had a number of phases or different emphases. Whether the shifting goals are called "skills" or something else, it is irrelevant. The goals are just different. One systematisation of "skills" goals at university law schools involves three historical waves or phases. ${ }^{13}$

First, traditional skills are those numbered 1, 2, 3, 5 and 8 - that is, the ability to manipulate and critique rules in thought, word and writing. These are the dominant skill goals of most western law schools of both yesterday and today.

The second wave of skills goals emerged particularly in the 1970s with the clinical legal education movement.

These skills are particularly numbered 4, 12 and 13 . That is, the skills of paper and people management, interviewing, negotiating, drafting, advocacy, spotting ethical issues and devising appropriate responses to these. The second wave of skills also frequently has/had a goal of inculcating values to serve the poor and oppressed. ${ }^{14}$

The third wave of skills also emerged in the 1970s in Canada, USA, Australia, UK and New Zealand particularly in postgraduate courses organised by Continuing Legal Education (CLE) and Professional Legal Training (PLT) trainers. These skills are particularly those numbered 4, 7, 9, 12 and 13 . That is, interviewing, negotiating, managing paper, advocacy, drafting basic correspondence and technical documents (eg pleadings) and spotting ethical issues and options.

In the 1980s, particularly new law schools began consciously to develop this third wave of skills largely in-house. This was done for a variety of reasons including niche marketing of graduates, overcoming staff and student boredom, attracting government and professional funding and reducing the cost of clinics.

Additionally, some teacher-learners had an intuitive sense and/or discovered theories that rule based learning (eg. torts, contracts, criminal law) took place at a deep level ${ }^{15}$ when incidentally required during skills exercises such as interviewing, drafting or advocacy.

In Australia in the 1990s recession added yet another reason for the growing interest of law schools in third wave skills. Publicly funded postgraduate professional legal training courses, havens for systematic skills learning, were contracting or closing. Moreover, many small law firms could no longer afford to spend time and money on skills training for new employees. Thus law schools, with varying degrees of willingness, stepped, stumbled or were dragged into the skills gap.

A notable addition to third wave goals, has been increased experimentation with "adult education" methods? ${ }^{16}$ One clear spin off from the third wave of "skill" goals, is an increased interest in educational theory and experimentation with learning methods at law schools. ${ }^{17}$ In passing it should be noted that interposed with these historic movements of skills goals were important phases of varying visibility in different countries which emphasised as educational goals certain values and ways of knowing - notably inter disciplinary studies, or law in context in the 1960s; environmental protection in the 1970s; and feminism and critical legal studies in the 1980s.

\section{FOURTH WAVE OF SKILLS?}

It is difficult to speculate on what new skills goals will emerge in many or some specialised law school curricula in the future. Problem identification and problem solving will probably grow in popularity (see traditional goals numbered 3, 4 and 11). This fourth wave will involve some law schools or individual law courses re-emphasising macro problem solving and social planning. ${ }^{18} \mathrm{~A}$ more likely scenario is that 
some/many law schools will become reluctantly committed to varying (and possibly improving) methods of teaching/ learning the knowledge and skills categorised in the first three waves. That is, the old goals "done better".

Hopefully, the fourth wave will also include both research and learning on a number of theories behind skills and professional lawyer behaviour. In the history of legal education, this visionary hope represents another elusive meeting of inter-disciplinary studies and grass roots "practical" behaviour. Or in other words, the gradual infiltration of theory into the learning of legal doctrine and skills.

In summary, three new directions are observable in the third wave of skills teaching which emerged in the 1970s:

1 New skill goals developed such as interviewing, listening, questioning, negotiating, managing people, managing paper, operating technology, managing stress, identifying and responding to ethical issues. These skills traditionally found only a small place in formal legal education goals and timetables (though are emphasised in the clinical legal education movement).

2 New knowledge goals very slowly developed behind the skills - namely the knowledge to systematise, analyse and critique the new skills. This "new" knowledge will inevitably be rooted in "old disciplines such as sociology, philosophy, ethics, economics and psychology. ${ }^{19}$

This remains undoubtedly the area which needs work - developing the knowledge and values behind lawyering skills. Although the acquisition and expression of knowledge and values inevitably require skills, the exercise of skill often takes place with minimal articulated theory and value superstructure. Thus the frequent cry that lawyering is a skilled, but not a learned profession - and therefore the profession is almost defenceless in the face of systematic critique.

3 Conscious application of adult educational methods. Methods rather than goals may prove to be the most enduring legacy of the 1970s skills movement, at least in university law schools. The market driven accountability of PLT and CLE courses "discovered" such educational orthodoxies as multiple learning styles, measurable goals, contract learning, self assessment, peer assessment, breaking down learning goals into small chunks, modelling, repetitive practice, and instant feedback.

Such orthodoxies are slowly creeping into comfortable and monopolistic university culture. The PLT and CLE tail has wagged the reluctant university dog. (Prodded also by economic rationalism, recession and student boredom).

Thus the skills movement of the 1970s is not "nothing new". It has emphasised and refined new skills, new knowledge (slowly) and new methods in formal legal educational cultures.

\section{SOME HURDLES AND CHALLENGES TO LEARNING THIRD WAVE SKILLS AT UNIVERSITY}

Those teachers who creatively seek to incorporate third wave skills into their doctrinal courses must necessarily be highly motivated and energetic. Anecdotally, they often express a number of frustrations or challenges as follows. ${ }^{20}$

\section{Time}

There is rarely enough time in the law student's diary to prepare for, execute and debrief (and try again) exercises on negotiation, drafting or advocacy.

\section{Lack of Systematic Curriculum Structure}

Even the most inspiring skills teacher rarely has any confidence that neophyte skills acquired in one course will be revised, reinforced, built upon in subsequent courses. The law school curriculum is standardly a scissors and paste jumble of unrelated stop-start topics administered by busy Lone Rangers. ${ }^{21}$

\section{Lack of Commitment}

Skills teachers, (like clinicians and interdisciplinary scholars) often discover a lack of commitment and vision from within and outside the law schools (including from Law Societies) concerning their interests. Skills are nominally tacked on to the tired old Langdellian model of a law school — segregated physically, 
lost in rarefied appellate casebooks, with little knowledge, skill, resources or desire to achieve multiple levels of competency in students. ${ }^{22}$ Many legal educators remain "[h]ypnotised by Langdell's ghost” and castrated by Langdell's economic model. ${ }^{23}$

\section{Resources}

Most classes would be improved by the presence of additional experienced instructors to model skills and provide instant feedback. There are rarely sufficient resources available to set up joint teaching programmes together with relatively small classes. ${ }^{24}$ Western legal education has marched willingly into the Langdellian trap of low cost - large lecture hall - appellate casebook education on the cheap and predictably has never recovered. ${ }^{25}$

All ideals are qualified by factors such as limited resources. If skills teaching is introduced in any substantial way in any law school (or elsewhere), what extra funds are available and what trade-offs are acceptable? Costonis ${ }^{26}$ comments:

Would the anticipated gains from accelerated competency outweigh the consequent sharp increase in law school tuition and upward pressure on the cost of legal services? Diversion of law school resources from scholarships, loanforgiveness programmes, and other forms of student financial aid to support all the additional expenses associated with expanded skills/values instruction? Concomitant reduction of access of the poor and minorities to legal education? Dilution or elimination of the substantive course offerings so prized by the bar? De-emphasis of the academic training that has enabled law school graduates to play such a productive role in shaping public policy of all types at all levels of government? Diminution of the research output - doctrinal and interdisciplinary — of nonclinical faculty, and retardation of ongoing efforts to integrate the law school with the university? Slowdown of current efforts to globalise and to introduce specialisation into the law school curriculum?

\section{Superficiality}

The majority of students appear to complete skills exercises demonstrating a veneer of engagement, creativity and insight. This may relate again to lack of time and overcrowding in the curriculum.

\section{Experiential Learning}

Many students appear to become highly motivated to learn skills only when confronted by flesh-andblood people paying or not paying for professional services. Are resources put into skills training without "real" clients justified if those skills appear to be learned so much more eagerly and quickly in a later and in another context?

Of course, the legal clinicians have practised answers to this well-worn question. ${ }^{27}$ Nevertheless, the question remains an important one as anecdotal praise continues for the focussed in-house education programmes such as "mentoring”, "orientation", and "monitoring” which take place within large law firms for new legal employees. ${ }^{28}$ These are sometimes new names for the much praised, traditional but elusive "good" articles-of-clerkship.

\section{"Mere” Training}

Teachers who articulate goals of acquisition of skills and also incorporate adult education methods into the learning environment, are sometimes assaulted with a form of snobbery which says that this is "mere" training or indoctrination, and is "spoon feeding". The counter suggestion of this critique is that there is a sophisticated form of "intellectual" or cognitive learning which cannot or should not be broken into systems which are easier to learn and assess.

In studies of the concept of "teaching" there have been regular attempts to distinguish educative or valued teaching from other kinds of activities with labels such as training, conditioning and indoctrination. ${ }^{29}$

But even the sometimes maligned concept of "training" appears to be redeemed if the training process engages analytical, systematic and critical thought and discussion. Robertson comments:

"Training” is used in a pejorative way less frequently than either "conditioning” or "indoctrination" and, accordingly, has a more substantial area of overlap with "educative teaching”. In many contexts, "teaching” can be substituted for "training" without a change in meaning. The focus of training is on the development of skills, on knowing- how rather than knowing-that (although, of course, a person may need to acquire a lot of propositional 
knowledge in the course of learning a complex skill). Sometimes "training" is reserved for use in the context of the teaching of routine tasks which allow total mastery, but this is by no means always the case. One can speak of the trained judgment of historians as well as of training a dog to jump through a hoop. When "training" does have a negative connotation by contrast with "educative teaching" (eg "He’s been merely trained rather than taught to think for himself"), the focus is on learning which is narrow, inflexible, and uninformed by the point of the activity undertaken. (Sometimes "drill” is used as the negative term and "train" as the positive one.) Teaching someone a skill, on the other hand, requires developing the learner's capacity to respond to the unexpected, to understand what he or she is doing and why, to be intelligent and reflective in the exercise of his or her skill. Such teaching therefore involves the giving of reasons rather than (or in addition to) drill. ${ }^{30}$

How can teachers of skills cultivate students who will become reflective practitioners?

\section{Labour Intensive Nature of Skills Training}

Teaching a skill well is a labour intensive task. It is very instructive to read the following quote about a model of teaching the skill of teaching which was developed from studies of successful teaching. It may be that this six stage process contains the elements of teaching any skill well. The word "teaching" in the quote can be substituted with skills like advocacy, interviewing, negotiation, mediation and so on.

"By isolating studies in which there is clear evidence that teaching behaviour has changed, the following components are seen as requirements for successful teacher education programmes:

a) A presentation of theory through readings, lectures, films, and discussions provides a rationale. The level of impact must be high enough so a trainee knows, in terms of theory, when, how, and why an instructional strategy is used.

b) Demonstrations and modelling help to translate theoretical images into a practical classroom setting. When films or video recording are used, there are often too few examples.

Many demonstrations may be required to help a teacher locate situations in which a model is inappropriate and to learn how a model can be adapted. The level of impact should include several practical examples for each concept in the model and to imagine adaptations and modifications of the model.

c) Practice under simulated conditions facilitates learning a skill or model because the teacher is less distracted by the complex responsibilities of a normal classroom. Practice is essential and closely related to the next three components.

d) Structured feedback means being systematic, learning a system of interaction analysis, or using a checklist to analyse one's own teaching. A cycle of teach-analyse-reteach can be repeated as often as necessary.

e) Unstructured feedback consists of informal discussion with a colleague which, of course, may be limited in terms of that person's ability. Informal discussion helps to create awareness of a problem, may be good for brain storming, and may give the trainee courage to continue.

f) Coaching is to have the assistance of a colleague or supervisor when the teacher trainee adapts a skill or model to the full size classroom. Adapting and adjusting patterns of teaching is much easier as a two-headed task, especially when the new model is quite different than one's natural style.

The idea of having a coach act as the midwife of a teaching innovation is unique and interesting. The role would be much more active than serving as a partner for an informal discussion. It would take joint planning and smooth cooperation."31

It is obviously very tempting to for any legal academic to avoid these complex tasks involved in skills teaching, and to invest his/her time in other priorities (eg research, writing).

\section{Teaching Burnout}

The complex nature of teaching skills well, often appears to result in teacher exhaustion after an initial period of several years of zealous activity. What strategies exist to reduce such burnout?

\section{Structural and Institutional Disincentives}

Because law schools are part of universities, staff career paths are dominated by university traditions, culture and "publish or perish" ethos. This apparently inflexible culture has been particularly frustrating for 
legal clinicians who aspire to promotion and pay increases - likewise for skills teachers. Teaching interviewing and mooting (like teaching Introduction to Law) has not lead readily to the development of writing skills or the polishing of publishable articles. Additionally, writing about skills tends to require the writer to be well versed in educational theory and social science research methods (and to minimise anecdotes and war stories). ${ }^{32}$

Traditional rule collection and rule manipulation research do not spring readily from skills teaching. Little wonder that some clinicians and skills teachers express disillusionment about their future career paths. Their intrinsic interest in skills teaching needs some institutional encouragement. What career incentives and new structures can be provided for skills teachers?

\section{Hawthorne Effect ${ }^{33}$}

Skills programmes and legal clinics are often set up by workaholic, charismatic zealots. Their pilot programmes often appear to be successes against the odds. However, in this writer's experience, upon the founder's demise or promotion into another pilot programme, the skills programme frequently flounders. The programme has no institutional foundations of resources, personnel, cultural acceptance, sticks and carrots once the dynamism and adrenalin of the founder is gone.

How can skills teaching be given institutional stability to survive the ebb and flow of individual personalities?

\section{Skills Interfere with Coverage of Substantive Topics}

The legal curriculum is under constant pressure (sometimes based appropriately upon teachers' current research interests) to expand substantive areas of coverage at university - either as compulsory or elective "law" subjects. ${ }^{34}$ Symptomatic of this pressure are specialty streams of law in undergraduate degrees; and the trend towards a course work LLM becoming an add-on group of substantive subjects which were "missed" or not sufficiently specialised in during the undergraduate degree.

Adding compulsory or even optional skills modules or subjects (or any new compulsory modules or subjects!) to the curriculum tends to leave some teachers with a deep unease that substantive coverage has been superficial.

\section{Lack of Credibility of "Academics"}

A traditional view of law teachers who inhabit university culture is that they are detached from the socalled "reality" of business and legal cultures. Thus they lack on-going experience in interviewing, drafting, advocacy and negotiation to be competent in teaching such skills. Can universities develop appropriate hiring, consultancy and staff training policies to give credibility to skills teachers?

\section{Vagueness of Assessment Criteria}

The assessment of skills is not only itself skilled and labour intensive, but also lacks sufficiently objective criteria. Can thirty different client interviews be graded and ranked based on explicable (and defensible) criteria?

\section{Lack of Appropriate Teaching Materials}

Many law schools do not have the time, expertise or resources to develop appropriate teaching materials for integrated skills modules or skills subjects. As well as written books, simulations and case-studies, skills courses often require demonstration by videos and reflective self observation by use of videos.

\section{CONCLUSION}

Despite the range of hurdles or challenges to the teaching/ learning of "skills", there are a number of pressures accumulating for the teaching/learning of at least third wave skills to take place by better methods and with an integrated building block curricula, within and between educational institutions, and over a long 
period of time of lifelong learning (from high school to university to law school to PLT to CLE). Effective building blocks will obviously require regular visits and secondments between classrooms and institutions.

Once again, it is likely that market driven PLT and CLE trainers will provide leadership in methods and assessment of skills training. The challenge for relatively docile and dramatically underfunded law schools in Australia is to develop a new breed of teacher/practitioner/social science researcher, who as individuals and in teams, can provide models and theories for skills training/learning. ${ }^{35}$ Without theory, skills are shallow and ephemeral. (Without reflection on skills, theory is marginalised). This task is not one for timid spirits.

\section{EXERCISE}

The latter part of this article has set out fourteen standard hurdles and challenges to teaching/learning skills at law school in the same order as discussed previously. Almost no attempt has been made to respond to these predictable objectives. In the writer's experience, some of these objections have on occasion reflected comfortable habit, fear, laziness and profound ignorance. Those foibles only make the genuine hurdles even higher.

Set out below is a possible exercise for an individual or for a law faculty group via pyramiding or brainstorming. ${ }^{36}$

The fourteen challenges to teaching skills at law school are set out in one column and a range of probable and improbable responses are invited in the blank column. These pages may be photostated and enlarged. Brainstorming responses can be written by individuals, articulated and clarified by interview, and systematised on whiteboards. (No model answers are available). Given the sometimes reluctant inevitability of skills teaching and learning, every law teacher and law school needs to address these challenges sooner rather than later.

\begin{tabular}{|l|l|}
\hline $\begin{array}{l}\text { CHALLENGES TO } \\
\text { TEACHING SKILLS }\end{array}$ & RESPONSES \\
\hline Not enough student time & \\
\hline $\begin{array}{l}\text { Lack of systematic } \\
\text { structure in the whole law } \\
\text { school curriculum }\end{array}$ & \\
\hline $\begin{array}{l}\text { Lack of resources - } \\
\text { human and financial }\end{array}$ & \\
\hline $\begin{array}{l}\text { Lack of commitment by } \\
\text { staff, legal profession and } \\
\text { university }\end{array}$ & \\
\hline $\begin{array}{l}\text { Superficial learning } \\
\text { patterns by students }\end{array}$ & \\
\hline $\begin{array}{l}\text { Learning takes place best } \\
\text { in “real life" experience } \\
\text { outside university }\end{array}$ & \\
\hline $\begin{array}{l}\text { Mere “training” is } \\
\text { inappropriate to a } \\
\text { university }\end{array}$ & \\
\hline $\begin{array}{l}\text { Labour intensive nature of } \\
\text { skills training and } \\
\text { assessment }\end{array}$ & \\
\hline Teacher burnout & \\
\hline $\begin{array}{l}\text { Structural and institutional } \\
\text { barriers (eg. lack of }\end{array}$ & \\
\hline
\end{tabular}




\begin{tabular}{|l|l|}
\hline promotion; publication) & \\
\hline $\begin{array}{l}\text { Hawthorne effect (success } \\
\text { of pilot projects) and } \\
\text { problems of succession }\end{array}$ & \\
\hline $\begin{array}{l}\text { Unease about decreasing } \\
\text { substantive “coverage” as } \\
\text { extras are added to the } \\
\text { curriculum }\end{array}$ & \\
\hline $\begin{array}{l}\text { Lack of credibility of } \\
\text { academics to teach skills }\end{array}$ & \\
\hline $\begin{array}{l}\text { Vagueness of criteria to } \\
\text { assess skills }\end{array}$ & \\
\hline $\begin{array}{l}\text { Lack of appropriate } \\
\text { teaching materials }\end{array}$ & \\
\hline Other challenges/hurdles? & \\
\hline
\end{tabular}

* Professor, School of Law, Bond University. Thanks to Raewyn Boyd and Janina Riley for typing several drafts. This article is a revised version of a paper presented at a conference on Teaching Skills at Bond University in February, 1994. The author is particularly grateful for critiques of a draft version by Marlene Le Brun and Richard Johnson.

1 The Concise Oxford Dictionary (London: OUP 1976).

2 K Mackie, Lawyers' Skills: Educational Skills in K Mackie, N Gold \& W Twining, Learning Lawyers Skills (London: Butterworths, 1989) at 9.

3 W Twining, Pericles and the Plumber (1967) 83 L Q Rev 396.

4 The goals of legal education have traditionally been broader than, but still embrace, suggested elements of lawyer "competency". See F Z Zanans \& V G Rosenblum The Making of a Public Profession (Chicago: ABA, 1981); J de Groot, Acquiring Basic Legal Skills and Knowledge: What, Where, By Whom and Why? APLEC Conference, Canberra, Nov 1993.

5 eg. D A Binder, P Bergman and SC Price Lawyers as Counselors (St Paul: West, 1991); G Egan The Skilled Helper (Wadsworth: California, 1994)

6 "Ethical dilemmas" should not be narrowly defined. Every conversation with a client is a moral conversation on how humans ought to behave. Ethics is not constrained to the "hard cases". See generally the writing of Thomas Shaffer. A lawyer inevitably makes conscious or subconscious choices between a range of options (whether the lawyer is aware of those options or not), and therefore bears some responsibility for what (s)he does. (S)he cannot hide behind the platitude of "just following the client's instructions”. See R Gordon, The Independence of Lawyers (1988) 68 BUY Rev 1; W Simon, Ethical Discretion in Lawyering (1988) 101 Ham L Rev 1083; S Burns, Teaching Legal Ethics (1993) 4 Legal Educ Rev 141.

7 eg. Australian Law Reform Commission, Equality Before the Law: Women's Equality ALRC 69, Part II (Sydney: Alken Press, 1994) ch. 8 on Legal Education; R Graycar and J Morgan Hidden Gender of Law (Sydney: Federation Press, 1990).

8 J O Mudd and J W La Trielle, Professional Competence: A Study of New Lawyers (1988) 49 Montana Law Rev 11

9 Ibid Mudd and La Trielle at 17-18.

10 eg. B S Bloom, M D Engelhart, E J Furst, W H W and D R Krathwohl, Taxonomy of Educational Objectives New York: McKay, 1956; A Petter, A Closet within the House: Learning Objectives and the Law School Curriculum in N Gold (ed) Essays on Legal Education (Toronto: Butterworths, 1982); P Ramsden, Learning to Teach in Higher Education (London: Routledge, 1992) ch 8; A N Whitehead The Aims of Education (New York: Macmillan, 1929); W G Perry, Cognitive and Ethical Growth: The Making of Meaning in Forms of Intellectual and Ethical Development in College Years: A Scheme (New York: Holt, Rinehart and Winston, 1970).

11 See R Gordon, Critical Legal Studies as a Teaching Method (1988) 1 Legal Educ Rev 59 at 77-83 (Demystify the law of contracts by drilling students in the orthodox arguments and counter arguments which attach to orthodox fact patterns); J Wade, Meet MIRAT: Legal Reasoning Fragmented into Learnable Chunks (1990-91) 2 Legal Educ Rev 283 (use of a popular five stage process in micro problem solving).

12 J Ellul, Propaganda (New York: Random House, 1965) (The aim of propaganda is to make the subject ad; internal belief and commitment will follow or rationalise action); L Festinger, A Theory of Cognitive Dissonance (Evanston Ill: Row, Peterson, 1957) (Socialisation can create cognitive dissonance by requiring patterns of conforming behaviour; internal commitment/rationalisation will usually follow.)

13 For an interesting historical analysis of the substantive goals and changing teachingstyles in US legal education, see Twining, supra note 3; R Stevens Law School: Legal Education in America from the 1850s to the 1980s (Chapel Hill: Uni of North Carolina Press 1983); D Weisbrot, Australian Lawyers (Melbourne: Longman, 1990) at 122-136.

14 Boyer and Cramton observe, - “(T)he following advantages of clinical teaching have been suggested: (1) clinical teaching makes it possible to deal with a greater range of skills and abilities, thereby avoiding the repetitiveness of the normal curriculum; (2) clinical methods can draw upon the emotional dynamics of role adjustment and role obligations to provide new motive force for learning; (3) the law clinic creates an atmosphere of camaraderie and co-operation between students and teachers, rather than polarising the "two cultures"; and (4) the clinical opportunity to demonstrate competence in "real world" situations can enhance and restore student self-esteem. These claims are highly plausible, but thus far evidentiary support for them has been sparse, "per B B Boyer \& R C Cramton, American Legal Education: An Agenda for Research and Reform (1973-74) 59 Cornell L Rev 221 at 281-282. 
Ramsden, supra note 10; R F Mager, Preparing Instructional Objectives (California: David S Lake, 1984).

7 Eg L D Solomon, Perspectives on Curriculum Reform in Law Schools: A Critical Assessment (1992) 1 U Toledo L Rev 24 (examples of innovative methods and goals at a number of US law schools); Legal Education Review 1989-1994; A Petter, A Closet Within the House: Learning Objectives and the Law School Curriculum in Essays on Legal Education ed N Gold (Toronto: Butterworths, 1982); yearly teaching workshops for legal academics conducted by the Australasian Law Teacher's Association (ALTA); B Boer, The Australian Law Teaching Clinic: Its Past, Present and Future, (1989) 1 Leg Educ Rev 145; postgraduate courses on Legal Education at Bond University, 1991-1994; M Le Brun \& R Johnstone, The Quiet (R)evolution - Improving Student Learning in Law (Sydney: Law Book, 1994)

18 See number 11 supra at 176; H D Lasswell and M S McDougal, Legal Education and Public Policy: Professional Training in the Public Interest (1943) 52 Yale L J 203; D Pearce, E Campbell and D Harding, Australian Law Schools: A Discipline Assessment for the Commonwealth Tertiary Education Commission (Canberra: AGPS, 1987) — the Pearce Report; Social Sciences and Humanities Research Council of Canada, Law and Learning (Ottawa: 1983) — the Arthurs Report; Law Schools and Professional Education (Chicago: ABA 1980) - the Cramton Report; Legal Education and Professional Development - An Educational Continuum (Chicago: ABA, 1992) - the McCrate Report; E de Bono Teach Your Child How to Think (New York: Penguin, 1992); see A G Amsterdam, Clinical Legal Education - A 21st Century Perspective (1984) 34 J of Leg Ed 612; see also the extensive literature on "Problem Based Learning" (PBL) — eg Probe, Newsletter of the Australian Problem- Based Learning Network, c/- PROBLARC, PO Box 555, Campbelltown, NSW 2560, Australia; id Le Brun \& Johnstone at 92-97.

19 D Schön, The Reflective Practitioner (New York: Basic Books, 1983); Educating the Rejective Practitioner (New York: Jossey Bass, 1987); C M Judd, E R Smith and L H Kidder Research Methods in Social Relations (New York: Harcourt Brace Jovanovich, 1991).

20 J M Hyman, Discovery and Invention: The NITA Method in the Contracts Classroom (1991) 66 Notre Dame Law Rev 759.

21 L G Solomon, Perspectives on Curriculum Reform in Law Schools: A Critical Assessment (1992) 1 U Toledo L Rev, 24.

22 Compare medical educational models - eg J J Costonis, The MacCrate Report: of Loaves, Fishes, and the Future of American Legal Education (1993) 43 J of Leg Educ 157; R Cramton, Professional Education in Medicine and Law: Structural Differences, Common Failings, Possible Opportunities, (1986) 34 Clev St L Rev 349.

23 J Frank, Both Ends Against the Middle, (1951) 100 U Pa L Rev 20 at 29. In Australia, the colonial replicant of that mindset and model was challenged for a time in the 1970s and 1980s by the postgraduate professional legal training colleges - see the Journal of Professional Legal Education.

24 Compare H Astor \& C Chinkin, Teaching Dispute Resolution: A Reflection and Analysis (1990) 2 Leg Educ Rev 1 (interactive coteaching model).

25 Contrast the ideals of the MacCrate Report - supra note 18. In Australia the Federal Government has exhibited no interest in funding any changes to a century-old model of cheap education but meanwhile is concerned about the competency and cost of lawyering practices. See C McInnis \& S Marginson Australian Law Schools after the 1987 Pearce Report DEET Higher Education Division, Evaluations and Investigations Program (AGPS. Canberra, 1994).

26 Costinos, supra note 22 at 191.

27 Eg see the classic articles by J Frank, Why Not a Clinical Lawyer- School? (1933) 81 U Pa L Rev 907; "Both Ends Against the Middle (1951) 100 U Pa L Rev 20.

28 Eg Costonis supra note 22 at 174-175

29 E Robertson, Teaching and Related Activities in M Dunkin (ed) The International Encyclopedia of Teaching and Teacher Education (Sydney: Pergamon, 1987); Ramsden supra note 10.

30 Robertson id at 16-17.

31 N A Flanders, Human Interaction Models in Dunkin supra note 29 at 26-27.

32 See Judd et a1 supra note 19; I Moses, Academic Work Reconsidered (1992) 35 Aust Rev 5; G Smith, The Regulation of Academic Employment: The Past and Present (1992) 35 Aust Rev 8.

33 The Hawthome effect occurs when participants know that they are engaged in an important or pilot experiment, and thereby their level of productivity improves dramatically. This effect was recorded from an experiment in 1927 in the Hawthorne Plant of Western Electric in Cicero, Illinois, USA — see F J Landy \& D A Trumbo, Psychology of Work and Behaviour (Homewood: Illinois, 1980).

34 In 1993 in Australia, a committee known as The Priestly Committee, decided that every future university law degree should include eleven compulsory detailed areas of knowledge in order to achieve national recognition across state borders. These eleven areas of knowledge are now embodied in the Uniform Admission Rules, rule 3(b). This decision has met with widespread criticism for lack of consultation, lack of educational theory, lack of monitoring machinery and lack of understanding of modem and emerging legal services, industries and subcultures. The Law Council of Australia has proposed a National Standards and Appraisal Committee: see Blueprint for the structure of the legal profession: a natural market for legal services (Canberra: Law Council of Australia, 1994) at 16-17.

35 The McCrate Report supra note 18 provides a helpful model of breaking many skills such as problem-solving, interviewing, negotiation, drafting and factual investigation into processes and sub-skills.

36 eg. G Gibbs, S Habeshaw \& T Habeshaw, 53 Interesting Things to do in your Lectures (Bristol: Technical and Educational Services Ltd, 1987). 